\title{
Numeric simulation of the interaction between subsonic flow and a deformable profile blade on the compressor experiment phase
}

\author{
Mekhonoshina E.V., Modorskii V.Ya., Petrov V.Yu. \\ Perm National Research Polytechnic University
}

\begin{abstract}
The article investigates the numeric simulation of two-way aeroelastic processes applied to the experimental phase of a compressor; physical, mathematical, rigid and grid models of the system "gas - rotor stator" have been worked out; 2 FSI (two-way Fluid-Structure Interaction) calculations have been performed on the evaluation of the interaction between a gas-dynamic flow and a deformable rotor blade; the effect of voltage gain is found in a blade, in an aeroelastic state compared with the transient calculations of a stress-strain state.
\end{abstract}

Keywords: interdisciplinary calculation, experimental compressor stage

Citation: Mekhonoshina E.V., Modorskiy V.Ya., Petrov V.Yu. Numeric simulation of the interaction between subsonic flow and a deformable profile blade on the compressor experiment phase. Proceedings of Information Technology and Nanotechnology (ITNT-2015), CEUR Workshop Proceedings, 2015; 1490: 211-218. DOI: 10.18287/1613-0073-2015-1490-211-218

\section{Introduction}

During the operation of compressors diverse vibrations may come out together with increased dynamic loads on the bearings; they can initiate the decrease of operating characteristics [1].

Blade machines produce vibrations for different reasons. For example, there might be technological imbalances of shafts and other rotation parts, or imbalances by assembly - all lead to vibrations. It's also necessary to consider vibration processes in magnetic suspensions. Vibration processes in labyrinth seals and in a gas-dynamic tracks are also taken as key vibration factors [2, 3, 4, 5].

Moreover, the analysis of vibration and aerodynamics is carried out separately due to the complexity of the calculations. Nowadays the vibrations in compressors cannot be predicted as essential factors and are not taken into account.

\section{Survey}

The history of aeroelastic numeric calculations traces back to works related to an asymmetric flutter that occurred during the flight on the bomber built by Handley Page. In 1918 after the failure of the lower wing of the biplane Albatros D3 German 
physicist Paul Richard Heinrich Blasius was the first to perform the analytical calculations of a flutter. First numeric calculation of the aerodynamic power acting on a harmonically vibrating thin plate in a two-dimensional flow was performed later in 1922 by W. Birnbaum in his thesis at Gottingen University [6, 7].

Since that time many researchers have referred to such issues of aeroelasticity. In 1972 A.S. Volmir described forced vibrations of the plate that was exposed to a periodically varying transverse load [8]. The issue of aerohydroelasticity and its component parts is thoroughly investigated in the following work [9]. The authors consider the tasks where the impact of environment on structures operation is necessary to consider and emphasize the always expanding scope of such tasks [9]. The main trend of the advance in technology is the increase of energy-and-mass characteristics; hence loads are increasing and the mass of structures reduces at the same time the stiffness of structures is coming down. In such a case unpredictable effects might occur, such as a "flutter". These kinds of issues are researched in the following works [2]. The authors take a gas-elastic approach to calculate vibration modes in power installations, give physical and mathematical models of a process, and suggest a unified algorithm and solution method [2]. Lots of model task solutions are given.

The researchers from the USA [10] did a review of associated numeric schemes. They took one of the approaches to study the issue of a flutter [10]. The scientists from three countries (ie. - China, Australia and USA), studied together the vibration of wind turbine blades [11]. In the calculations the authors paid attention to the interaction of gas flow and structure in the applied software ANSYS. The scientists stress that the effect of such an interaction is essential and it has to be considered [11]. The scientists from China write about the interaction of a gas-dynamic flow and structure with the profile NACA0012 [12]. Together with the idea of the following work [2] it's being suggested that the deformations change the flow field around the structure, while the change in the field of a gas-dynamic pressure flow affects the deformations as well [14].

As shown in [9] the solution of aeroelastic tasks requires theoretical methods of elasticity, aeromechanics and vibrations. It's necessary to simulate interdisciplinary physical phenomena in order to solve such tasks. It's complicated to calculate together aerodynamics and rigidity as we deal with different mathematical models, solution methods, the dynamics of calculated areas and approaches to discrete the equations.

There are two variants of associating the equations of rigid body dynamic deformation and the equations of gasdynamics: monolithic and consecutive [3]. By a monolithic approach we use numeric schemes which result in the formation and subsequent solution of a unified system of algebraic equations. A consecutive approach is used to solve associated interdisciplinary tasks based on a separate solution by the systems of equations for each subtask and requires the implementation of calculation data exchange between the subtasks over a set period of time $[3,13]$ with help of iteration procedures. Otherwise the synchronization is performed directly. Such an approach is implemented in well known commercial products, such as ANSYS, FlowVision, Abacus, CCM+, SolidWorks, LS-Dyna, Sysnoise NASTRAN, OpenFOAM and FEStudio [14]. 


\section{Physical model}

This work suggests a fully associated non-standardized solution scheme for an aeroelastic task applied to the simulation in the dynamical system "gas-rotor-stator interaction" on the example of a compressor experiment phase.

Two domains have been considered: inlet guide vane (IGV) and the rotor itself. The domain IGV is permanent, rotor domain is rotating with a constant angular rate. The interaction of a gas-dynamic flow and rotor blade deformation is being considered. Three-dimensional calculation model is given in the figure 1.

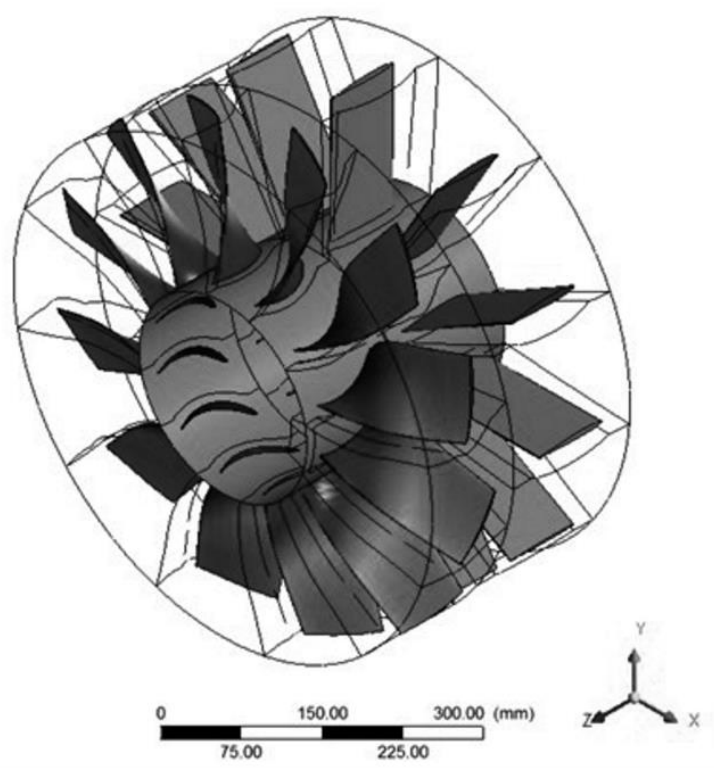

Fig. 1. - Three-dimensional calculation model of a compressor

We look at the sector that takes $1 / 12$ of the structure. The sector is bounded by the planes on which symmetry conditions are written. We consider the flow of an ideal gas with the set properties; chemical processes are not considered; one-phase flow; the calculations are performed without taking into account gravitation; the walls of the structure neither absorb nor give off heat; the walls of the structure are rugged; the coefficients of heat capacity don't depend on the absolute temperature.

\section{Mathematical model}

Mathematical model is worked out based on the chosen physical model; mathematical model includes two submodels. The submodel of gasdynamics is based on the conservation laws of mass, momentum, energy, the equation of state of the ideal compressible gas and encloses with the initial and boundary conditions. Boundary conditions for gasdynamics are shown in the figure 2 . 


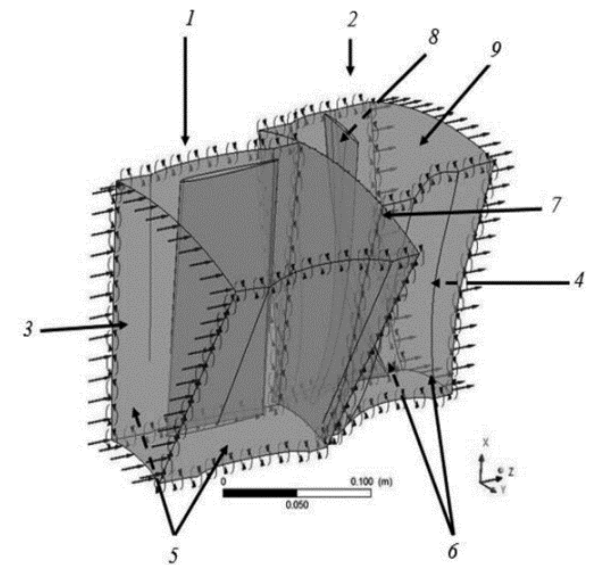

1 - stator domain, 2 - rotor domain, 3 -input, 4 - output; 5 - stator domain symmetry, 6 - rotor domain symmetry, 7 - interface between the domains, 8 - the interface "gas - structure" (movable grid of a rotor blade), 9 - movable grid of the gap in the rotor domain

Fig. 2. - Boundary conditions for gas dynamic calculation

Mathematical model for the evaluation of a stress-strain state is written down as follows $[15,16]$ :

$m \ddot{x}+c \dot{x}+k x=F(t)$

Where $m$ - mass matrix; $c$ - damping matrix; $k$ - rigidity matrix; $F(t)-$ load vector; $x$-displacement.

At each moment these equations can be considered as a set of static equations of equilibrium which take up the forces of inertia and damping as well. Time integration by the Newmark method is used to solve these equations $[15,16]$. We calculate the increment between subsequent time points, integration step. Boundary conditions for the structure are shown in Figure 3.

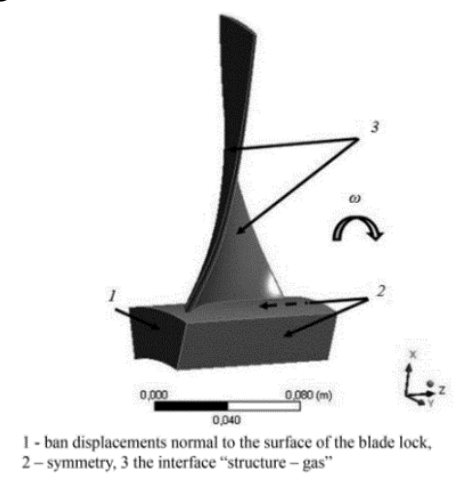

Fig. 3. - Boundary conditions for stress-strain state calculation 
Afterwards we developed rigid body and grid models of the structure and gas dynamic part. The number of the elements of the grid model of a gas dynamic rotor track made up 56482 nodes and 51750 elements; of a gas dynamic stator track 51863 nodes and 47490 elements; structures - 7728 nodes and 3378 elements.

\section{Computational experiments}

The solution is found by the iteration way. Two solvers - Transient Structural (transient mechanics, finite element approach) and CFX Transient (gas dynamics, finite volume approach) - are connected by data transfer. For the flow diagram of such a solution refer to the following work [11].

The calculations are performed in the system of the computer engineering analysis ANSYS 15.0 using the power of the high performance computing complex of PNRPU. The duration of the calculations averages 4 hours on 16 cores «IntelXeon E5-2680». We believe that the application of hybrid supercomputing systems with graphics accelerators has great potential [17].

\section{Results}

According to the results of the computational experiments we found that the dependence of the increment of displacements is specified by the aeroelasticity from rotation speed at the control point which is located on the upper edge of the blade. Figure 4 shows the diagram where in the vertical axis the difference of displacements is given received by the calculation 2FSI and transient calculations of a stress-strain state (calculated by the formula: $\Delta U=U_{2 F \mathrm{SI}^{-}} U_{\text {transient }}$ ).

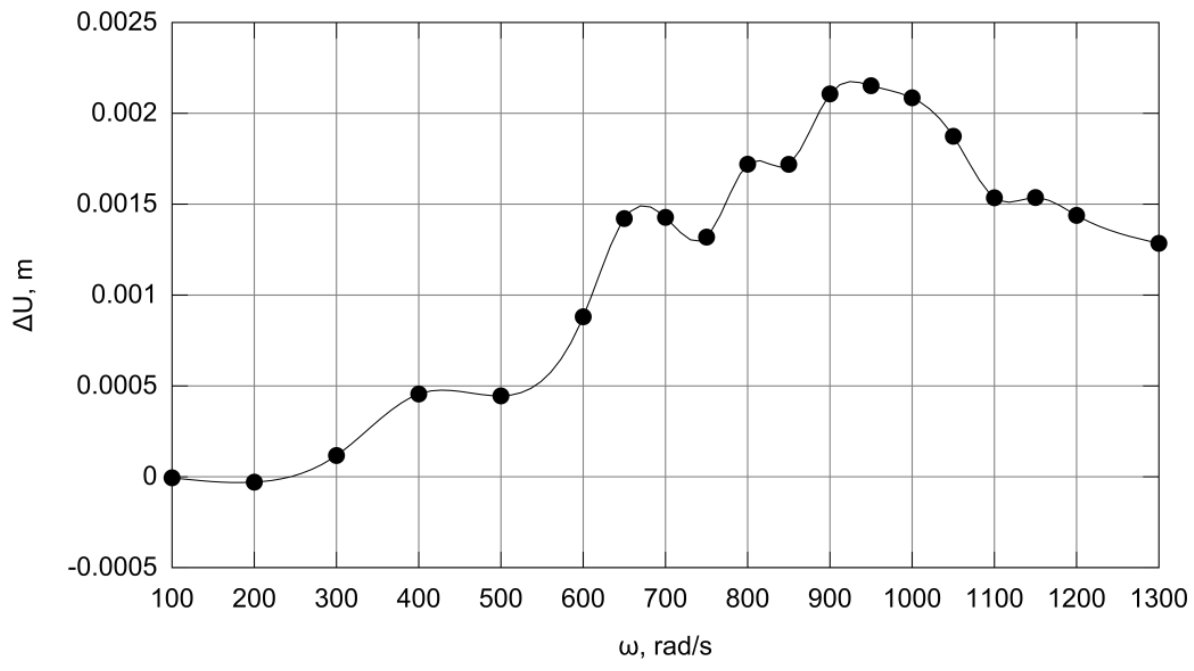

Fig. 4. - Aeroelasticity impact on the full movements at the control point on the upper edge of the blade

In the horizontal axis the rotation of rotor speed is given. For the analysis we selected the points which fit the period of time of the second peak occurrence by the calculations 2FSI. At the same time the critical frequency of the rotation of the 
compressor model phase was determined by the Campbell diagram which made up $1013,8 \mathrm{rad} / \mathrm{s}$ that determines the increase of movements by the rotation at the speeds close to the critical speed.

In the computational experiment we received the dependence of the von Mises stress $\sigma$ time by the transient calculations (without considering FSI) and by the calculations 2 FSI for the rotor rotation speed $\omega=650 \mathrm{rad} / \mathrm{s}$ (see the figure 5).

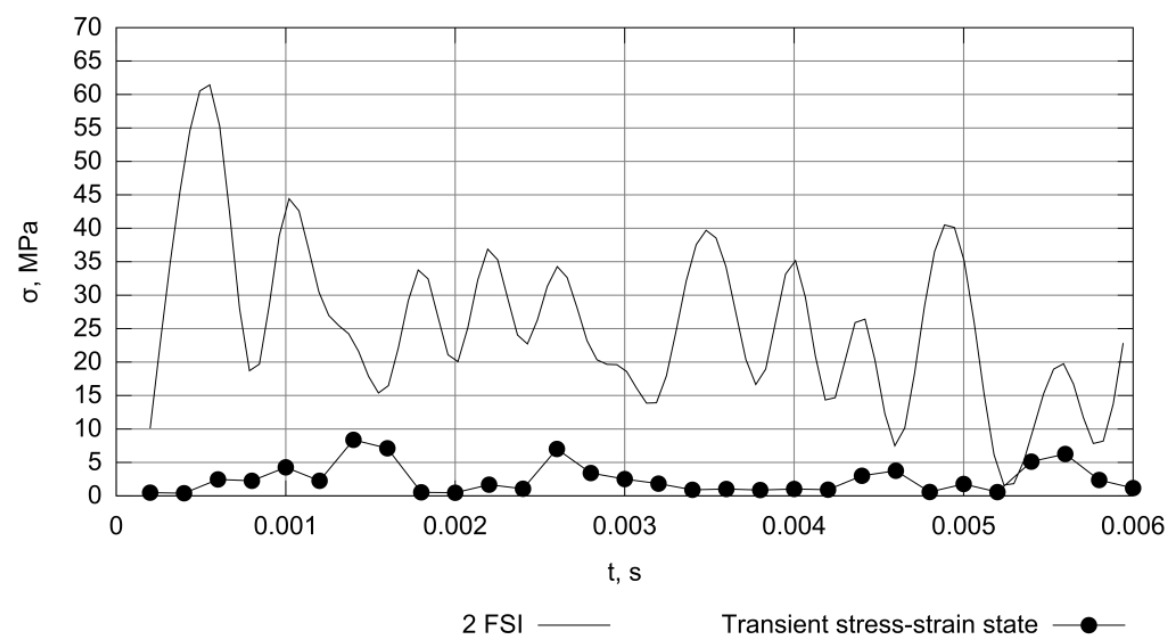

Fig. 5. - Von Mises stress $(\omega=650 \mathrm{c}-1)$

We carried out the analysis of these dependences by diverse speeds of rotor rotation. The following charts of the dependences $\Delta \sigma \max$ and $\Delta \sigma a v$ from $\omega$ were worked out (figure $6 \mathrm{a}, 6 \mathrm{~b}$ respectively), with $\Delta \sigma_{\max }=\frac{\sigma_{\max }^{F S I}-\sigma_{\max }^{\text {trans }}}{\sigma_{\max }^{\text {trans }}}$, $\Delta \sigma_{a v}=\frac{\sigma_{a v}^{F S I}-\sigma_{a v}^{\text {trans }}}{\sigma_{a v}^{\text {trans }}}$, where $\sigma_{a v}^{F S I}=\frac{\sum_{1}^{N} \sigma^{F S I}}{N}, \sigma_{a v}^{\text {trans }}=\frac{\sum_{1}^{N} \sigma^{\text {trans }}}{N}$.

We can see that at the frequencies close to the critical ones there is the increase of von Mises stress related with aeroelastic effect.

\section{Acknowledgements}

Therese archis financed by the grant of the Russian scientific fund (project №1419-00877). 


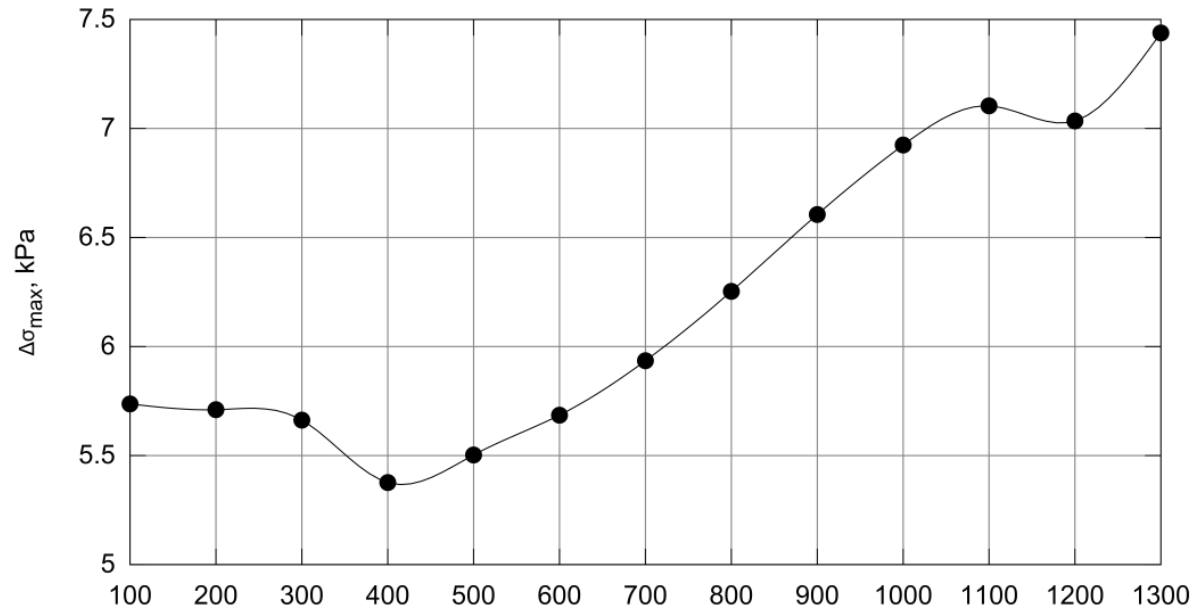

a)

$\omega, \mathrm{rad} / \mathrm{s}$

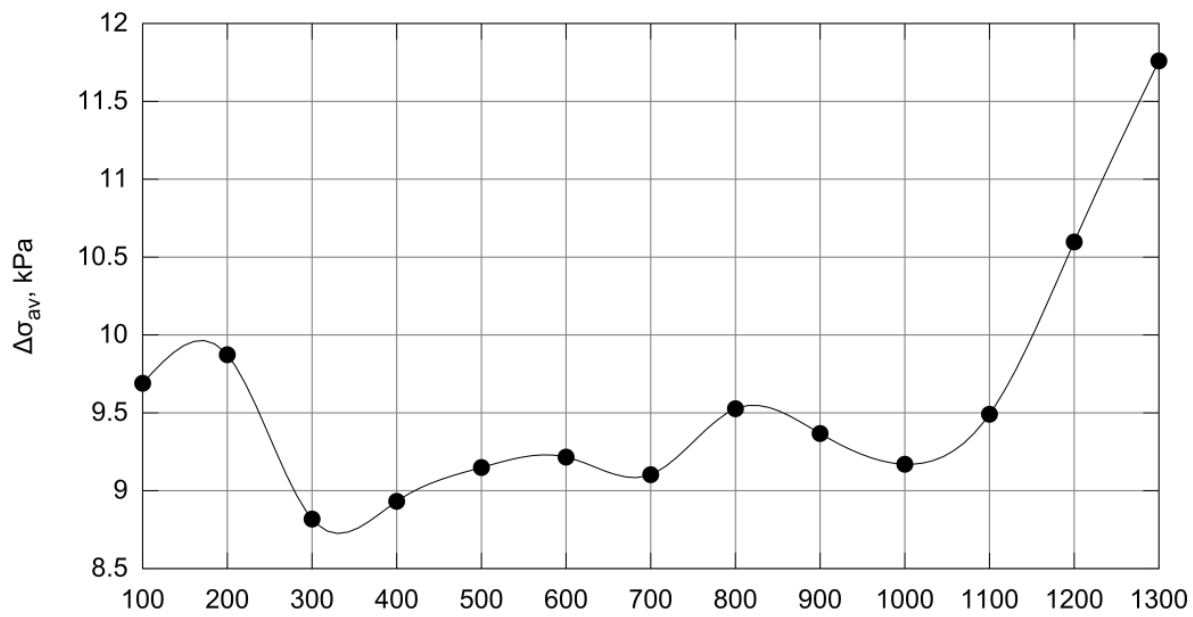

b)

$\omega, \mathrm{rad} / \mathrm{s}$

Fig. 6. - The increase of von Mises stress by considering aeroelastic effect: a - by maximum values; $b$ - by average values

\section{References}

1. Mekhonoshina EV, Modorsky VYa. Development of a technique of numerical modeling of the aeroelastic work of Compressor. Scientific and technical bulletin of the Volga region, 2014; 5: 264-268. [in Russian]

2. Modorsky VYa, Sokolkin YuV. Gas-elastic processes in power installations. Ed by Sokolkin YuV. Moscow: Nauka, 2007. [in Russian]

3. Kopysov SP, Tonkov LE, Chernova AA. Bilateral binding when modeling interaction of a supersonic stream and deformable plate. Comparison of numerical schemes and results Experiment. Computational Continuum Mechanics, 2013; 6(1): 78-85. [in Russian] 
4. Amarantov GN, Egorov MYu, Egorov SM, Egorov DM, Nekrasov VI. Numerical modeling of intra chamber processes at an exit to an operating mode of the rocket engine of solid fuel. Computational Continuum Mechanics, 2010; 3(3): 5-17. [in Russian]

5. Ganeev MS, Moiseyev VE, Skvortsova ZV. A nonlinear bend and stability of the ellipsoidal cover interacting from Liquid. Computational Continuum Mechanics, 2011; 4(3): 32-40. [in Russian]

6. Arsentiev TP. The Abstract of the thesis "Fluctuations of a wing in a supersonic stream of gas": $\mathrm{PhD}$ thesis abstract physical and mathematical science. SPb. University, St. Petersburg, 2009; Source: <http://www.dissercat.com/content/kolebaniya-kryla-vsverkhzvukovom-potoke-gaza-0>

7. Blasius H. Über Schwingungserscheinungen an Einholmigen Unterflügeln. Zeitschrift für fFugtechnik und Motorluftschiffahrt, 1925; 16: 39-42.

8. Volmir AS. Nonlinear dynamics of plates and Covers. Ed by Kildibekov IG. Moscow: Nauka, 1972. [in Russian]

9. Gorshkov AG, Morozov VI, Ponomarev AT, Shklyarchuk FN. Aero hydroelasticity of designs. Moscow: Fizmatlit, 2000. [in Russian]

10. Xiangying Ch, Ge-Cheng Zh, Ming-Ta Ya. Numerical simulation of 3-D wing flutter with fully coupled fluid-structural interaction. Computers \& Fluids, 2007; 36: 856-867.

11. Jianping Z, Liang G, Helen W, Aixi Zh, Danmei H, Jianxing R. The influence of wind shear on vibration of geometrically nonlinear wind turbine blade under fluid-structure interaction. Ocean Engineering, 2014; 84: 14-19.

12. Hefeng D, Chenxi W, Shaobin L, Zhen SXi. Numerical Research on Segmented Flexible Airfoils Considering Fluid-structure Interaction. Procedia Engineering, 2015; 99: 57-66.

13. Farhat C, Lesoinne M. Two efficient staggered algorithms for the serial and parallel solution of three-dimensional nonlinear transient aeroelastic problems. Computer Methods in Applied Mechanics and Engineering, 2000; 182(3-4): 499-515.

14. Kopysov SP, Kuzmin IM, Rychkov VN, Tonkov LE. The divided approach at the solution of the connected problems of FSI on hybrid computing systems. Works of the international scientific conference "Parallel computing technologies (PAVT '2015)". Yekaterinburg: UrFU of the first President of Russia B. N. Yeltsin, 2015; 415-419. [in Russian]

15. ANSYS Structural Analysis Guide, Release 15.0. Source: <http://www.ansys.com/>.

16. Wang E, Nelson T. Structural Dynamic Capabilities of ANSYS. Source: <http:// easc.ansys.com/staticassets/ANSYS/staticassets/resourcelibrary/confpaper/2002-IntANSYS-Conf-200.PDF >.

17. Golovashkin DL, Loganova LV. Solution of difference equations difference scheme with cyclic boundary conditions on two-dimensional grid areas using multiple graphics computing devices. Computer Optics, 2012; 36(4):534-540. 